\section{Testosterone levels in men with chronic migraine}

Lisa B.E. Shields, 1 Tad Seifert, 1

Brent J. Shelton, ${ }^{2}$ Brian M. Plato ${ }^{1}$

1Norton Neuroscience Institute, Norton

Healthcare, Louisville, KY;

2The Markey Cancer Center, University

of Kentucky School of Medicine,

Lexington, KY, USA

\begin{abstract}
Chronic migraine is a frequent and debilitating condition affecting $14 \%$ of the general population. This prospective observational pilot study investigated whether men with chronic migraine have lower than expected total serum testosterone levels. We identified 14 men ages 26-51 at our Institution who fulfilled the ICHD-3b criteria for chronic migraine and obtained serum total testosterone levels. The mean total testosterone level in our 14 patients was 322 $\mathrm{ng} / \mathrm{dL}$ (range: 120-542 $\mathrm{ng} / \mathrm{dL}$ ) which is in the lower $5 \%$ of the reference range for our laboratory (300-1080 $\mathrm{ng} / \mathrm{dL})$. Men with chronic migraine had lower total testosterone levels compared to published agematched normative median values by a median difference of $62 \mathrm{ng} / \mathrm{dL}(\mathrm{P}=0.0494)$. This finding suggests that hypothalamic regulation is altered in patients with chronic migraine. Further studies are warranted to determine whether testosterone supplementation in men with chronic migraine reduces the number of headaches or the associated symptoms of hypogonadism.
\end{abstract}

\section{Introduction}

Migraine is a common, multifactorial, disabling primary headache disorder.1,2 According to the International Classification of Headache Disorders, $3^{\text {rd }}$ edition (beta version), chronic migraine refers to a headache occurring on 15 or more days per month for more than 3 months which has the features of migraine on at least 8 days per month. ${ }^{2}$ According to the National Health Interview Survey in 2012 , the overall prevalence of migraine or severe headache is $14.2 \%$ in the United States, with $19.1 \%$ of females and $9.0 \%$ of males affected with substantial variations depending on age. ${ }^{3}$ Migraine ranked as the third most common cause of disability worldwide in individuals under 50 as reported by the Global Burden of Disease
Survey 2015.4 Migraines are considered to involve the hypothalamus, brainstem, and cortex which regulates autonomic, affective, cognitive, and sensory functions. ${ }^{1}$ Chronic migraine may affect hypothalamic hormonal secretion. Many men with chronic migraine exhibit symptoms that are frequently seen with hypogonadism (depressed mood, reduced energy, difficulty concentrating).

Positron emission tomography (PET) has shown hypothalamic activation in spontaneous migraine attacks which persists after headache relief by sumatriptan. ${ }^{5,6}$ Attention has focused on the function of the hypothalamus in circadian rhythms, pain control coordinating the activity of the sympathetic and parasympathetic nervous systems, and in maintaining homeostasis. ${ }^{1,5,7}$ In addition, the hypothalamus is integrally involved with the body's responses to stress. ${ }^{7}$ The hypothalamus secretes gonadotropin-releasing hormone (GnRH) which stimulates the anterior pituitary gland to release luteinizing hormone $(\mathrm{LH})$ from the gonadotrophs. ${ }^{8}$ The receptors for LH are located on Leydig cells in the testis which synthesize testosterone following LH stimulation. ${ }^{8}$ Figure 1 depicts the hypothalamic regulation of testosterone.

There are no reports known to the authors on the effect that chronic migraine may have on testosterone levels in men. We investigated whether men with chronic migraine have lower than expected total serum testosterone levels. In this prospective pilot study, we present our findings pertaining to the interaction between chronic migraine and testosterone levels. We also discuss the impact of chronic migraine on the regulation of the hypothalamo-pituitarygonadal axis.

\section{Materials and Methods}

\section{Patient population}

Under an institutional review board (IRB) approved protocol, we prospectively identified 14 men who fulfilled the ICHD$3 \mathrm{~b}$ criteria for chronic migraine without opioid or barbiturate overuse at our Institution. These patients were evaluated by a neurologist at our Institution's outpatient clinic in a metropolitan community. All men obtained serum total testosterone levels. These values were compared to the local laboratory normal values and to published agematched controls. ${ }^{9}$

\section{Statistical analysis}

Data are presented in listings and summarized as either mean (SD) or median
Correspondence: Brian M. Plato, Norton Neuroscience Institute, Norton Headache and Concussion Center, Norton Suburban Hospital, 3991 Dutchmans Lane, \#310, Louisville, KY 40207 USA.

Tel.: +1.502.8996782 - Fax: +1.502.8996783. E-mail: Brian.Plato@nortonhealthcare.org

Key words: Neurology, Migraine, Testosterone, Hypothalamus, Hypogonadism.

Acknowledgements: the authors acknowledge Norton Healthcare for their continued support. They also acknowledge Douglas John Lorenz, Ph.D., Andrew J. Shearer, B.S., and Lauren A. Shelton, for their contributions to this work (data management and data checks for quality).

Contributions: LS made substantial contributions to the conception and design, analyzed and interpreted the data, performed the literature search, and was the major contributor in the writing of the manuscript. TS and BP made substantial contributions to the conception and design, analyzed and interpreted the data, and revised the draft critically for important intellectual content. BS is the statistician who performed the statistical analysis in this work and also contributed to the conception and design, analyzed and interpreted the data, and revised the draft critically for important intellectual content.

Conflict of interest: the authors declare no potential conflict of interest.

\section{Funding: none.}

Conference Presentation: Presented as a poster at the 57 th Annual Scientific Meeting of the American Headache Society, June 18-21, 2015, Washington, D.C. U.S.A

Received for publication: 21 February 2019.

Revision received: 14 April 2019.

Accepted for publication: 14 April 2019.

This work is licensed under a Creative Commons Attribution NonCommercial 4.0 License (CC BY-NC 4.0).

(C) Copyright L.B.E. Shields et al., 2019 Licensee PAGEPress, Italy

Neurology International 2019; 11:8079 doi:10.4081/ni.2019.8079

(interquartile range: $25^{\text {th }} \%$-tile $\& 75^{\text {th }} \%$ tile). To test whether the testosterone distribution amongst those men with migraines differed from a control population distribution, the median testosterone from a published age-specific control population was matched to the age-specific testosterone level for the 14 migraine subjects. ${ }^{9}$ To assess whether these age-matched groups differed, Wilcoxon Signed Rank test was 
used to test for the testosterone distribution difference. An a-priori two-sided significance level of $5 \%$ was used to interrogate any observed difference.

\section{Results}

A total of 14 men fulfilled the criteria for inclusion. The mean age was 36.1 years (range: 26-51 years). The local laboratory normal range for total testosterone was 300 $1080 \mathrm{ng} / \mathrm{dL}$. Table 1 illustrates the total testosterone levels of migraine patients compared to published age-matched controls. The mean total testosterone level in the 14 patients with chronic migraine was $322 \mathrm{ng} / \mathrm{dL}$ (range: 120-542 ng/dL).

For published age-matched controls, the mean total testosterone level was $384 \mathrm{ng} / \mathrm{dL}$ $(\mathrm{SD}=10.3)$. Six males (43\%) had testosterone levels below the minimum of the normal local laboratory range. Men with chronic migraine had lower total testosterone levels compared to published agematched controls by a median difference of $62.0 \mathrm{ng} / \mathrm{dL}$ (interquartile range of 0.34 to 130). The Wilcoxon Signed rank statistic revealed a statistically significant difference between the two distributions ( $\mathrm{P}=0.0494)$.

\section{Discussion}

In our pilot study, men with chronic migraine had statistically significant lower total testosterone levels compared to an age-matched normative population, suggesting that hypothalamic regula- tion is altered in patients with chronic migraine. We propose that the suppression of the hypothalamic pituitary axis as a result of chronic migraine inhibits the release of GnRH resulting in secondary hypogonadism. A host of studies have investigated the pathophysiology of the hypothalamus in both cluster headache 10 and chronic migraine, 1,5-7,11 however, a paucity of studies have explored the interaction between testosterone levels and chronic migraine, tension type headache (TTH), and cluster headache.12,13 It has been suggested that both male and female sex hormones could influence the course of primary headaches, specifically, tension-type headache, migraine, and cluster headache. ${ }^{14}$ Romiti and colleagues studied plasma testosterone levels in cluster headache and non-cluster headache controls. ${ }^{13}$ Plasma testosterone levels were significantly lower during the cluster attack and were within the reference limits in the remission period of episodic cluster headache. ${ }^{13}$ These authors suggest that a decrease of plasma testosterone levels in episodic cluster headache should be considered in relation to disordered rapid eye movement (REM) sleep in cluster headache.

The present study and that of Romiti et al. highlighted testosterone levels in migraine and cluster headache, respectively. ${ }^{13}$ Both studies reported that testosterone levels were significantly lower in the headache disorder group compared to controls. We demonstrated that men with chronic migraine had lower total testosterone levels compared to their agematched control by a median difference of $62 \mathrm{ng} / \mathrm{dL}$ (interquartile range of 0.34 to
130). In addition, there was a statistically significant difference between the two distributions $(\mathrm{P}=0.0494)$. Six males $(43 \%)$ had testosterone levels below the minimum of the normal local laboratory range. Of note, the mean total testosterone level in our 14 patients with chronic migraine was 322 $\mathrm{ng} / \mathrm{dL}$ which is in the lower $5 \%$ of the reference range for our laboratory (300-1080 $\mathrm{ng} / \mathrm{dL})$. This finding supports that testosterone levels are very low in migraine patients. Abnormality of the hypothalamuspituitary-gonadal axis is believed to be involved in the pathogenesis of migraine. ${ }^{15}$ In Li and colleagues' study of the levels of HPG axis hormones serum FSH, LH, estradiol, progesterone, testosterone, prolactin, and GnRH, they reported that these hormones were abnormal in migraineurs and were associated with migraine-related clinical characteristics. ${ }^{15}$

Hypogonadism refers to "a clinical syndrome that results from failure of the testis to produce physiological levels of testosterone (androgen deficiency) and a normal

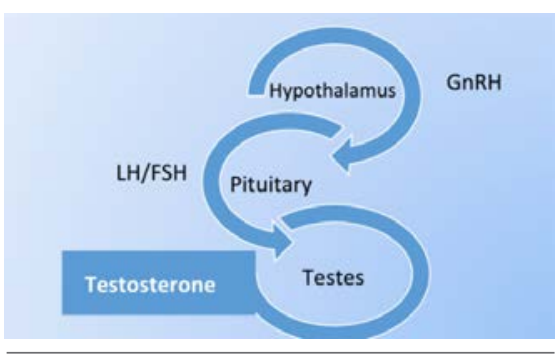

Figure 1. Hypothalamic regulation of testosterone.

Table 1. Total testosterone levels of migraine patients compared to published age-matched controls.

\begin{tabular}{|c|c|c|c|}
\hline Age & $\begin{array}{l}\text { Total testosterone of } \\
\text { migraine patients (ng/dL) }\end{array}$ & $\begin{array}{l}\text { Normal for reference } \\
\text { lab }(1=\text { yes; } 0=\text { no })\end{array}$ & $\begin{array}{l}\text { Total testosterone of published } \\
\text { age-matched controls ( } \mathrm{ng} / \mathrm{dL} \text { )* }\end{array}$ \\
\hline 26 & 406 & 1 & 406 \\
\hline 27 & 428 & 1 & 403 \\
\hline 30 & 120 & 0 & 392 \\
\hline 32 & 434 & 1 & 386 \\
\hline 33 & 270 & 0 & 383 \\
\hline 33 & 324 & 1 & 383 \\
\hline 34 & 378 & 1 & 383 \\
\hline 35 & 268 & 0 & 380 \\
\hline 37 & 542 & 1 & 378 \\
\hline 38 & 360 & 1 & 378 \\
\hline 40 & 230 & 0 & 375 \\
\hline 42 & 310 & 1 & 375 \\
\hline 48 & 196 & 0 & 375 \\
\hline 51 & 245 & 0 & 375 \\
\hline
\end{tabular}

Normal Testosterone Range (Local Reference Lab): 300-1080 ng/dL. *See Kelsey et al. 2014.9 
the accompanying symptoms of hypogonadism.

one or more levels of the hypothalamicpituitary-testicular axis". 16 Hypogonadal symptoms include diminished libido, fatigue, poor concentration, erectile dysfunction, and depressed mood in the setting of low serum testosterone levels. ${ }^{17}$ Many men with chronic migraine exhibit symptoms that are frequently seen with hypogonadism, specifically, depressed mood, reduced energy, and difficulty concentrating. Testosterone supplementation has been shown to be beneficial in improving both hypogonadal symptoms and serum total testosterone levels. ${ }^{16,17}$ Testosterone therapy in hypogonadal men has been shown to be highly effective and safe for improving lower urinary tract symtpoms, cardiometabolic risk, and major adverse cardiovascular events 18 as well as urinary and sexual function and quality of life. 19 Testosterone serves as a neuroprotective agent, 20 suggesting a valuable role in the treatment of chronic migraine. Continuous testosterone has also been reported as beneficial in reducing the severity of migraines in both pre- and post-menopausal women. ${ }^{21}$ These studies demonstrate that testosterone effectively treats migraine headaches in both men and women and that low testosterone is likely causal and not the result of migraines.

The strength of the present study is the prospective evaluation of the possible role of testosterone in migraine headaches as it is far less studied than estrogen/progesterone. Our study is limited by its small sample size. Prospective, randomized studies with a larger sample size are warranted to permit generalizability of our results.

\section{Conclusions}

In this pilot study, men with chronic migraine had statistically significant lower total testosterone levels compared to an age-matched normative population. Further investigation is necessary to determine whether testosterone supplementation in men with chronic migraine reduces either the number of headache days per month or

\section{References}

1. Burstein R, Noseda R, Borsook D. Migraine: multiple processes, complex pathophysiology. J Neurosci 2015; 35:6619-29.

2. Headache Classification Committee of the International Headache Society (IHS). The International Classification of headache Disorders, 3rd edition (beta version). Cephalalgia 2013;33:629-808.

3. Burch RC, Loder S, Loder E, et al. The prevalence and burden of migraine and severe headache in the United States: updated statistics from government health surveillance studies. Headache 2015;55:21-34.

4. Steiner TJ, Stovner LJ, Vos T. GBD 2015: migraine is the third cause of disability in under 50s. J Headache Pain 2016;17:104.

5. Alstadhaug KB. Migraine and the hypothalamus. Cephalalgia 2009;29:809-17.

6. Denuelle M, Fabre N, Payoux P, et al. Hypothalamic activation in spontaneous migraine attacks. Headache 2007;47:1418-26.

7. Cortelli P, Pierangeli G. Hypothalamus and headaches. Neurol Sci 2007;28: S198-202.

8. Handa RJ, Weiser MJ. Gonadal steroid hormones and the hypothalamo-pituitary-adrenal axis. Front Neuroendocrinol 2014;35:197-220.

9. Kelsey TW, Li LQ, Mitchell RT, et al. A validated age-related normative model for male total testosterone shows increasing variance but no decline after age 40 years. PLoS One 2014;9: e109346.

10. Leone M, Bussone G. A review of hormonal findings in cluster headache. Evidence for hypothalamic involvement. Cephalalgia 1993;13:309-17.

11. Peres MF, Sanchez del RM, Seabra ML, et al. Hypothalamic involvement in chronic migraine. J Neurol Neurosurg
Psychiatry 2001;71:747-51.

12. Aksoy D, Solmaz V, Cevik B, et al. The evaluation of sexual dysfunction in male patients with migraine and tension type headache. J Headache Pain 2013; 14:46.

13. Romiti A, Martelletti P, Gallo MF, et al. Low plasma testosterone levels in cluster headache. Cephalalgia 1983;3:41-4.

14. Delaruelle Z, Ivanova TA, Khan S, et al. Male and female sex hormones in primary headaches. J Headache Pain 2018; 19:117.

15. Li W, Diao X, Chen C, et al. Changes in hormones of the hypothalamic-pituitary-gonadal axis in migraine patients. J Clin Neurosci 2018;50:165-71.

16. Spitzer M, Huang G, Basaria S, et al. Risks and benefits of testosterone therapy in older men. Nat Rev Endocrinol 2013;9:414-24.

17. Ramasamy R, Wilken N, Scovell JM, et al. Effect of testosterone supplementation on symptoms in men with hypogonadism. Eur Urol 2015;67:176-7.

18. Saad F, Doros G, Haider KS, et al. Hypogonadal men with moderate-tosevere lower urinary tract symptoms have a more severe cardiometabolic risk profile and benefit more from testosterone therapy than men with mild lower urinary tract symptoms. Investig Clin Urol 2018;59:399-409.

19. Haider KS, Haider A, Doros G, et al. Long-term testosterone therapy improves urinary and sexual function, and quality of life in men with hypogonadism: results from a propensity matched subgroup of a controlled registry study. J Urol 2018;199:257-65.

20. Fargo KN, Foster AM, Sengelaub DR. Neuroprotective effect of testosterone treatment on motoneuron recruitment following the death of nearby motoneurons. Dev Neurobiol 2009;69:825-35.

21. Glaser R, Dimitrakakis C, Trimble N, et al. Testosterone pellet implants and migraine headaches: a pilot study. Maturitas 2012;71:385-8. 